\title{
La enunciación plural y las formas disensuales en Tala de Gabriela Mistral*
}

\author{
The plural enunciation and the disensual forms \\ in Tala by Gabriela Mistral
}

Magda Sepúlveda Eriz ${ }^{* *}$

\section{RESUMEN}

Gabriela Mistral elaboró en Tala un americanismo que no consiste en hablar por otros, sino en crear una enunciación plural, un "nosotros" andino. En la identificación de la voz poética con el mundo andino, más que una representación de las culturas de los Andes, la escritora opta por trazar otro modelo de percepción para la zona. Mistral consigue desplazar las líneas de representación habitual acerca de la comunidad andina. Entre las formas disensuales concebidas por Mistral están la creación de otros referentes territoriales para América, la constitución de un colectivo político de enunciación y la valoración de los conocimientos incaicos. Todos estos aspectos se hacen visibles en el poema "Cordillera", el que se vuelve el modelo ejemplar de Tala.

\begin{abstract}
Gabriela Mistral developed an Americanism in Tala that consists not of speaking for others, but instead constructing a plural enunciation, an Andean we. By identifying the poetic voice in the Andean world, rather than a representation of the cultures of the Andes, the writer chooses to trace another model of perception for the area. Mistral manages to displace the usual lines of representation of the Andean community. The dissensual forms conceived by Mistral are the creation of other territorial references for Latin America, the constitution of a political collective of
\end{abstract}

Palabras clave: Gabriela Mistral, andino, poesía chilena, Rancière.

Keywords:

Gabriela Mistral, Andean culture, Chilean poetry, Rancière.

Este artículo se inscribe dentro del proyecto Fondecyt № 11.60.191, "Llaneros solitarios, fisiatras y sampleadores. Artes poéticas, manifiestos y proclamas de la poesía chilena".

* $\quad$ Chilena. Doctora en Literatura por la Universidad de Chile. Académica titular del Departamento de Literatura de la Universidad Católica de Chile. msepulvu@uc.cl 
La enunciación plural y las formas disensuales en Tala de Gabriela Mistral | Sepúlveda

enunciation and the appreciation of Incan knowledge. All of these aspects can be seen in the poem "Cordillera," which can be considered the exemplary model of Tala. 


\section{Introducción}

La gran mayoría del territorio chileno está flanqueado por la cordillera de los Andes, volviéndose una referencia constante para los connacionales. Pese a ello, el país no se reconoce a sí mismo como andino, en parte porque el imaginario nacional que se originó en el siglo XIX potenció las culturas que están entre el mar y la cordillera ${ }^{1}$. Esa visión ligó la creación de la identidad nacional oficial al valle central, con su correspondiente figura, el huaso ${ }^{2}$, relegándose así la conciencia de las altas montañas de los Andes y de los personajes cordilleranos que habitan en ella. Sin embargo, la poesía de Gabriela Mistral ejerció una fuerza contraria ${ }^{3}$.

\section{Contexto del libro Tala y presentación del concepto "formas disensuales"}

El libro Tala (1938) ${ }^{4}$ se "inscribe dentro de los textos poéticos mistralianos que elaboran con mayor propiedad la cultura andina” (Sepúlveda 100). Para los efectos de acercarse a este mundo, consideraremos el marco de los estudios transandinos, los que permiten emanciparse de "lo andino" como espacio asociado coloquial y exclusivamente a la puna, es decir, a las mesetas ubicadas sobre los 3.700 metros de altura y concebidas, en general, viviendo en un tiempo pasado estático y marginal a la modernidad. Por el contrario, la noción de culturas transan-

\footnotetext{
1 Esta construcción deja relegada no solo a la cordillera, sino también al mar como lo hace ver el historiador Cristián Gazmuri: "El hecho es que Chile - que es pura costaculturalmente ha mirado hacia la tierra y no hacia el mar; su arquetipo humano es el huaso" (29).

"El huaso fue el símbolo del mundo rural, defendido por los criollistas como el personaje que mejor representaba la idiosincrasia y el particularismo nacional. [...]. La vinculación del huaso con los caballos, el rodeo y con las destrezas del campo, su vestimenta de origen andaluz, cordobesa e incaica, e incluso, en ocasiones su lenguaje, son atributos tanto del patrón como del peón. El huaso, tanto en la realidad como en la ficción es - a diferencia del roto- un personaje transclase, un canal no de confrontación, sino de hibridaje social, de intercambio de visiones de mundo y valores" (Subercaseaux 336- 338).

3 Otros poetas chilenos que han tomado lo andino en distintos momentos de su producción son Cecilia Vicuña, Soledad Fariña y Raúl Zurita

4 En 1938, Mistral viaja a Argentina, aceptando la invitación de Victoria Ocampo, a quien había conocido en Madrid. Mistral tenía un manuscrito de Tala, que Ocampo publicó bajo su sello, Sur, el más prestigioso en Latinoamérica en esa época. Tala es en parte una respuesta a la Guerra Civil Española (1936-1938), lo cual se aprecia en su mención a los niños del Orfanato Basque, donde se atendía a los huérfanos, y también en su invitación a los europeos a venirse a América Latina.
} 
dinas permite referir a zonas de altura, pero también a regiones que están a los pies y a media altura de la cordillera, lo que implica prácticas más variadas de las que se ejercitan solo en la puna. Además, hablar de culturas transandinas ${ }^{5}$ permite salir de la idea de pueblo originario, es decir, pegado al origen, y plantearlos como pueblos con pasado, con diversos periodos históricos, pero a la vez actuales.

El momento transandino de la fragmentación de la zona andina en territorios nacionales corresponde al periodo en que Gabriela Mistral desarrolla su escritura. En Tala, la poeta emprende una mirada más allá de lo nacional: ella imagina una región andina a partir de su andar por el continente, por eso su subjetividad se inscribe como transandina. La vecindad cultural en que se escribe Tala corresponde a un momento de reflexión en torno a América Latina. El crítico Mauricio Ostria explica que el poemario "coincide con una serie de trabajos ensayísticos que procuran descifrar los signos de nuestra cultura, como es el caso de las obras de José Vasconcelos, Samuel Ramos, Antonio Caso, Alfonso Reyes, Pedro Henríquez Ureña, Mariano Picón Salas, José Carlos Mariátegui, Antenor Orrego, Ricardo Rojas, Manuel Ugarte, Aníbal Ponce y Ezequiel Martínez Estrada" (82). En ese contexto, Mistral elabora su idea de una comunidad latinoamericana formada por los campesinos, razón por la que el estudioso Jaime Concha caracteriza la propuesta como "humanismo rural" (3334). Considerando estos aspectos, nosotros deseamos precisar que el humanismo americano de Mistral no consiste en hablar por otros, sino que en reconocerse en un "nosotros" andino desde el cual sitúa su lugar de enunciación.

La vanguardia de Mistral no fue el experimentalismo de los años 30, sino traer al presente y hacer visibles las formas retóricas del mundo incaico. En otras palabras, la avant-garde de Mistral fue usar y construir

La idea de "culturas transandinas" fue propuesta por varios investigadores para referirse a comunidades que se destacaban por su movilidad espacial en las zonas de los Andes. Ellos distinguen un primer periodo histórico donde las diversas comunidades indígenas del altiplano andino y regiones colindantes forman un complejo cultural común. El segundo periodo corresponde a la instalación del Virreinato del Perú. El tercer momento se caracteriza por la fragmentación de la zona andina en estados nacionales, en las que destacan discursos nacionalistas, indigenistas y americanistas; y el cuarto, más contemporáneo, está definido por las migraciones diaspóricas intra, inter y transnacionales (Bernaschina y Bosshard, “Introducción..." 927). 
con los signos andinos su lugar de enunciación. Ella evitó describir a otros como indígenas, como diferentes a la voz enunciadora - gesto propio del indigenismo ${ }^{6}$ - , cuya forma de lenguaje contribuye a crear un grupo diferente al de la autoría del texto. Por el contrario, Mistral experimentó con el lenguaje antiguo, donde los himnos al sol, las rogativas y las rondas, entre otros géneros discursivos, vuelven al presente de la enunciación. A través de todas estas "formas disensuales" frente al repertorio de la vanguardia chilena, Mistral solicitó los derechos de tierras para los indígenas.

La noción de formas disensuales fue propuesta por el filósofo de la estética Jacques Rancière en su libro El espectador emancipado (2008). Su idea es comprender el arte como una "experiencia de disenso" (62), vale decir, el arte como una ruptura con el régimen de percepción:

las estrategias de los artistas que se proponen cambiar las referencias de aquello que es visible y enunciable, de hacer ver aquello que no era visto, de hacer ver de otra manera aquello que era visto demasiado fácilmente, de poner en relación aquello que no lo estaba, [es el trabajo] que cambia los modos de presentación sensible y las formas de enunciación [estableciendo] la constitución de colectivos políticos de enunciación. (Rancière 66-67)

Las formas disensuales cambian las coordenadas de lo representable, constituyen otros colectivos de enunciación, modifican la forma en que los sujetos nos relacionamos, definen otras capacidades y tolerancias, y pueblan el mundo de otros sucesos, personajes y figuras.

\section{Las formas disensuales en el poema "Cordillera"}

La hipótesis de este artículo es que Mistral produce formas disensuales respecto de la manera en que la cultura nacional ha mirado lo andino. Entre estas formas destaca la creación de otros referentes territoria-

\footnotetext{
$6 \quad$ La crítica literaria hace diferencias entre la literatura indigenista y la literatura indígena. Uno de los mayores estudiosos de este asunto es Antonio Cornejo Polar. Para él, "la literatura indigenista no abre un nuevo sistema comunicativo en cada uno de los países andinos y se limita a discurrir por el cauce que es propio de la literatura culta, si se quiere oficial" ("El indigenismo..." 19). Este "proceso de producción obedece a normas occidentalizadas o europoides, [tanto] por la posición social y cultural de sus productores [cuanto] por el contexto en que actúan y las convenciones culturales y literarias que emplean" (18).
} 
les para América; el diseño de un nosotros de conciencia andina, con saberes y modelos discursivos pertenecientes a esa región cultural; la invitación al levantamiento a través del modelo del himno y de la rogativa; y la valoración de los conocimientos incaicos, estableciendo allí un centro de legitimidad simbólico distinto del imperio de los signos del español. Todos estos aspectos se hacen visibles en el poema "Cordillera", el que se vuelve por esto el modelo ejemplar de Tala.

Frente a la separación en naciones, Mistral opta en Tala por construir otro espacio territorial, una región latinoamericana andina unificada. Para crear la integración, considera que el espacio cultural privilegiado es la cordillera de los Andes. En el poema "Cordillera", la poeta extiende la zona andina desde el Estrecho de Magallanes hasta Venezuela. Y no solo eso, Mistral hace partir la cordillera en el Estrecho, dando vuelta el mapa. Examinemos la dirección del recorrido:

desde mi Estrecho a Santa Marta,

subiendo de las aguas últimas

al unicornio del Aconcagua.

Pasas el valle de mis leches, amoratado en la higuerada;

cruzas el cíngulo de fuego

y los ríos Dioscuros lanzas

pruebas Sargassos (sic) de salmuera

y desciendes alucinada ... (99)

La cordillera poetizada sube desde el Estrecho de Magallanes, pasa por el monte Aconcagua ${ }^{7}$, y sigue por el valle de sus leches, es decir el del Elqui. Marcando su lugar de nacimiento por las higueras que la tierra produce allí, Mistral hace continuar la cordillera por el cinturón ${ }^{8}$ de fuego del Pacífico que involucra a Perú. Luego la prolonga por la parte alta de Colombia, donde nacen los ríos Dioscuros, que corres-

El monte Aconcagua se encuentra ubicado a $32^{\circ}$ latitud sur y $69^{\circ}$ longitud oeste. Tiene un grado de diferencia en ambas coordenadas de distancia respecto de Santiago de Chile, ubicado a $33.45^{\circ}$ de latitud y $70^{\circ}$ de longitud.

8 Cíngulo es "el cordón o cinta de seda o lino, con una borla a cada extremo, que sirve para ceñirse el sacerdote" (RAE, 1992). Mistral llama así al cinturón de fuego del Pacífico, que parte en Chile, sigue hasta la costa de California y finaliza en Japón. El nombre se debe a los volcanes submarinos y a las placas tectónicas inestables de ese lecho marino. 
ponden al Cauca y al Magdalena9. Mistral dice que la cordillera "lanza estos ríos", lo que es efectivo geográficamente, en tanto nacen desde ella. Además, la denominación "ríos Dioscuros" connota una agencia política para los Andes, pues la vuelve apta para la lucha, ya que los gemelos Castor y Pólux ${ }^{10}$, los Dioscuros, son guerreros. A partir de la frontera entre Colombia y Venezuela, Mistral hace descender a la cadena montañosa, sumergiéndola, y prolongándola imaginariamente hasta el mar de los sargazos ${ }^{11}$, ubicado en la costa atlántica de México, Cuba y Florida. La forma de describir los hitos de la cordillera es disensual del régimen de los hitos de fronteras nacionales, pues la poeta se centra en la flora terrestre y acuática de la zona. Si en el valle de Elqui era la uva, la costa atlántica del lugar va a ser mencionada a través del alga sargazo que se produce en ese mar. Finalmente la hace descender en Venezuela, sin mencionar el país, solo escribiendo unos puntos suspensivos que connotan el hundimiento paulatino. Este recorrido, que parte en el Estrecho de Magallanes, toma la dirección desde el sur hacia el norte. La alteración de la mirada hegemónica proporciona otra manera de entender el territorio latinoamericano.

Mistral se sitúa en una posición enunciadora geopolítica que está lejos de la casa del imperio español en cuanto a cómo este concibió el territorio. La región latinoamericana andina es comparada en el poema con las siete colinas de Roma:

\footnotetext{
9 Llamados ríos Dioscuros, porque son dos puntas que se transforman en una hebra. El río Magdalena se inicia en los Andes colombianos y drena hacia el mar Caribe. Tiene $1.290 \mathrm{~km}$ navegables. El Cauca, que también nace en los Andes, recorre buena parte de la geografía colombiana, antes de unirse al Magdalena (Vergara y Velasco 35). Ellos corren paralelos gran parte de su descenso antes de unirse, por ello se les denomina como los gemelos griegos, los Dioscuros.

10 Cástor y Pólux nacieron de los huevos de Leda como consecuencia de la unión con Zeus transformado en cisne. Eran llamados Dioscuros, es decir, hijos de Júpiter. Entre sus hazañas destaca la liberación de su hermana Helena del secuestro cometido por el ateniense Perseo. "Cástor y Pólux son dos héroes jóvenes, dos combatientes. El primero es especialmente guerrero; el segundo practica el boxeo" (Commelin 142). Además, libraron al archipiélago griego de los saqueadores. Otra gran hazaña fue ayudar a la conquista del vellocino de oro. Por su fuerza guerrera eran representados en medallas antiguas con figuras de robustos adolescentes, [unas veces] de pie, pica en mano, y otras en soberbios caballos blancos (288-289).

11 El mar de los sargazos se ubica en la costa atlántica abarcando las zonas de Venezuela (Isla Margarita), México, Florida y Cuba. Su nombre se debe a un alga café muy tupida. Fue considerado un mar peligroso para los buques a vela en el siglo XII y XIII (Oxford University Press 152).
} 
Caminas, madre, sin rodillas, dura de ímpetu y confianza con tus siete pueblos caminas en tus faldas acigueñadas, caminas de noche y de día (99)

Mistral dice "con tus siete pueblos caminas", aludiendo a los siete pueblos andinos: Chile, Argentina, Bolivia, Perú, Ecuador, Colombia y Venezuela, de modo que el verso sitúa el mundo andino en equivalencia con el mundo romano. Es una actitud decolonizadora ${ }^{12}$, puesto que dignifica la cultura latinoamericana de los Andes para mirar a las otras a la par.

En "Cordillera" la extensión de las culturas andinas integra al grupo de mapuches pehuenches que vive en la cordillera de los Andes, especialmente en la zona comprendida desde lo que hoy conocemos como los Nevados de Chillán hasta el volcán Llaima. Los mapuches pehuenches son nombrados metonímicamente a través del árbol, la araucaria, del que extraen el piñón con el que se alimentan:

Extendida como una amante

y en los soles reverberada,

punzas al indio y al venado

con el jengibre y con la salvia;

en las carnes vivas te oyes

lento hormiguero, sorda vizcacha;

oyes al puma ayuntamiento

y a la nevera despeñada,

$\mathrm{y}$ te escuchas el propio amor

en tumbo y tumbo de tu lava.

Bajan de ti, bajan cantando

como de nupcias consumadas

tumbadores de caobas

y rompedores de araucarias (100)

Esta estrofa está construida sobre los sonidos de la montaña. En los Andes, se escucha la vizcacha, se oye al puma, a las rocas despeñarse

12 Usamos la palabra "decolonial" en el sentido propuesto por Mignolo, que considera que hay que poner atención "desde dónde y a partir de dónde se piensa" (258) para salir de "habitar la casa del imperio" (260) y dar un "giro geo y corpo político frente a la teopolítica desincorporada y deslocalizada" (262). 
y a los mapuches sacudir las araucarias. Dos árboles de las cumbres andinas dominan en esta estrofa: la araucaria y la caoba. La madera roja de la caoba es usada para hacer muebles y por ello la tumban en los Andes colombianos y venezolanos. Mistral describe así la cordillera por los animales y pueblos que se relacionan con ella, incluyendo a los mapuches pehuenches que el imaginario nacional ha puesto fuera de las culturas andinas.

Mistral crea una forma disensual al procurar otros referentes territoriales que consideran una nueva forma de visibilizar el mapa latinoamericano y una forma de describir la cordillera por su flora, fauna y pueblos que la habitan, sin seguir el registro de los accidentes geográficos que se usan como hitos fronterizos. La segunda forma disensual consiste en la elaboración de un colectivo político de enunciación, que corresponde a un "nosotros" andino:

piedra Mazzepa (sic) que no se cansa,

Atalanta que en la carrera

es el camino y es la marcha

y nos lleva pecho con pecho,

a lo madre y lo marejada,

a maná blanco y peán rojo

de nuestra bienaventuranza (98)

La voz enunciadora reconoce su pertenencia al mundo cordillerano al posicionarse en la primera persona plural: "nos lleva" y luego llamarla "nuestra bienaventuranza". Este "nosotros" adquiere un carácter político al introducir como sustitución de la montaña la expresión "piedra Mazzepa". Mistral compara la cordillera con el héroe Mazeppa. El ucraniano Iván Mazeppa combatió a los rusos y a los polacos con el propósito de conservar la unidad territorial de Ucrania. Sus hazañas fueron exaltadas por el poema homónimo de Lord Bryon (1819). Mistral da por hecho que eso es un conocimiento común para los lectores y lo integra para connotar al mundo andino como factor de unidad política.

La cordillera recibe también el nombre de Atalanta ${ }^{13}$, que corresponde a una heroína griega cuya capacidad de correr era magnífica.

13 Atalanta, la extraordinaria corredora, no deseaba casarse, por ello, confiando en sus capacidades, dijo que solo lo haría con quien la venciera. Se casó efectivamente con el joven que la venció en la carrera. Gozaron de su amor en el santuario de Cibeles. La diosa 
Las montañas de los Andes se vuelven inatrapables por su extensión a lo ancho y no tan solo a lo largo. La inmensidad territorial la faculta como un espacio de refugio y resistencia cultural. Este segundo aspecto más desafiante tiene que ver con la introducción del vocablo "marcha" en el verso "es el camino y es la marcha". El significante "marchar" es propio de los himnos ${ }^{14} \mathrm{y}$ justamente este poema está en la sección "Dos himnos" del capítulo "América" de Tala. Solo que, en vez de fabricar un himno nacional, Mistral crea un himno andino.

El "nosotros" como colectivo político de enunciación es coherente con la opción del modelo poético del himno. Esta fue una elección realizada con plena conciencia por parte Mistral. En las notas que ella escribe para el final de Tala declara: "Suele echarse de menos, cuando se mira a los monumentos indígenas o la cordillera, una voz entera que tenga el valor de allegarse a esos materiales formidables" (276). La poeta encuentra necesario el tono mayor, pues el tono menor ya le suena empalagoso: "El que discuta la necesidad de hacer de tarde en tarde el himno en tono mayor, sepa a lo menos que vamos sintiendo un empalago de lo mínimo y de lo blando" (276). El tono monumental y solemne adquiere un punto culmine en las dos últimas estrofas "en las que se escuchan ecos de Bello y Martí y donde se anticipa por lo menos una de las imágenes principales de 'Alturas de Macchu Picchu"' (Rojo 266). La opción de alejarse del tono íntimo ${ }^{15}$ en la sección "Dos him-

de la Tierra, llamada después Rea, montó en cólera y los transformó en dos leones que tiran su carro (Grimal 57-58). Observando este mito, se aprecia que Mistral feminizó la cordillera de forma particular, asunto que amerita un estudio específico y profundo.

14 De acuerdo a The Princeton Encyclopedia of Poetry, los himnos nacionales tienen su origen en el siglo XIX, siendo el primero de ellos el himno holandes, "Het Wilhelmus". Los himnos nacionales se han construido con motivo de una crisis social, como "God save the king" en Inglaterra; de una revolución, "Marseillaise" en Francia o de una independencia como el himno turco. Todos ellos aspiran a ensalzar la cohesión social de un grupo mediante elogios al pueblo, al paisaje, a los símbolos patrios y a otros valores que se busca resaltar. A nivel melódico, la comunidad llega a estar presente bajo la forma de coro. Su valor performativo se reivindica en cada acción, en las marchas militares, en el primer día de clases y en los rituales deportivos, generando así el sentimiento de ser una colectividad.

15 Mistral también es consciente de usar un estilo de escritura para el himno que no es cercano a la tradición greco-latina: "Si nuestro Rubén, después de la Marcha Triunfal (que es griega o romana) y del Canto a Roosevelt que es ya americano, hubiese querido dejar los Parises y los Madriles y venir a perderse en la naturaleza americana por unos largos años - era el caso de perderse a las buenas- ya no tendríamos estos temas en la cantera; estarían devastados y andarían entonando el alma del mocerío" (276). 
nos" es plenamente consciente y marcará al siguiente premio Nobel chileno.

La conciencia de estar escribiendo un himno convoca al lector a seguir el protocolo de lectura de ese género que se distingue por su carácter performativo. Un himno une y levanta los ánimos. En el poema mistraliano, el himno alude a una escena comunitaria de recuperación activa de la dignidad andina. La palabra "peán" entrega un índice del carácter cercano a la protesta de este himno. "Peán"16 es una alusión compleja y letrada que refiere por un lado a los himnos griegos que alentaban a los guerreros y, por otro, a los volcanes de la cordillera. Ambos sentidos de "peán" no se anulan, al contrario, se potencian entre sí. La recuperación de la dignidad es también un volcán. Al vocablo "peán" se suman otras decisiones lingüísticas, como la presencia de la palabra "marcha". La cordillera es presentada como el espacio para la marcha, incluso la montaña "punza" invitando a caminar juntos para manifestarse. La cordillera es "la marcha" y no tan solo paisaje. El himno se canta y se marcha con él. En la misma línea funciona el significante "marejada" con que describe a los Andes, que se refiere a los picos de la cordillera, vistos como olas, y connota también una "marejada" de gente. No se trata solo del paisaje vacío de personas, sino de un espacio habitado. De ahí la mención a la condición alimentadora de la cordillera, a través de la frase "maná blanco". Entonces, Mistral está construyendo un pliegue entre la cordillera, como ente físico, y los cordilleranos como pueblos de reclamación política.

El poema "Cordillera" es un himno por la unidad andina cuya función apelativa está dirigida a la montaña. Esta apelación se asemeja a los ritos de adoración andina dirigidos a los Apu o señores de los cerros, cuya función más importante era proporcionar agua para la agricultura. En la medida en que el agua escurra, la Pachamama o manto de tierra cubrirá de vegetación el suelo y la fertilidad se extenderá a toda la localidad. Al ser lo invocado una montaña y definirse quien habla por un nosotros participante de la adoración, el poema

16 "Peán: Término griego (paian) con el que se designa un himno coral cantado en la antigua Grecia, y que estaba formado por un proemio del solista y un clamor ritual del coro a base del grito "ie paian". [....]. La función del solista podía desempeñarla el jefe militar, mientras que a los soldados o ciudadanos les correspondía el papel del coro" (Estébañez 818). 
se asemeja a una rogativa andina. A pesar de ello, Goic interpretó "Cordillera" como una letanía (32), pero nosotros postulamos al poema como una rogativa ${ }^{17}$. Este modelo discursivo implica entender el lugar asignado a la cordillera en los ritos ceremoniales andinos: "Montañas y lagunas ocupan un lugar de privilegio en las creencias y prácticas rituales que pueblan el mundo andino" (Ceruti 233). Se les rinde culto porque "las altas cumbres son concebidas como moradas de deidades atmosféricas y espíritus de los ancestros, a los que se cree íntimamente relacionados con la fertilidad y las lluvias. Es por ello que el culto a las montañas tiene antigüedad milenaria en la cordillera de los Andes. La lista de rasgos notables del paisaje que eran concebidos como huacas y adorados por los andinos en tiempo de los inca incluía cordilleras nevadas, cerros con riquezas mineras, lagunas de altura y el mar" (233). La novedad del modelo discursivo mistraliano es componer una rogativa que es a la vez un himno. La rogativa pide el levantamiento de los pueblos andinos hacia su dignidad.

La demanda política de unidad andina en Mistral está legitimada, por ella, en un pasado que corresponde al imperio inca. Dado que existió esa unidad, ella la recuerda como argumento de la formulación de su "nosotros" andino:

¡Cordillera de los Andes,

Madre yacente y Madre que anda,

[...] que en metales y en amiantos

nos aupaste las entrañas,

hallazgo de los primogénitos

Mama Ocllo y Manco Cápac

tremendo amor y alzado cuerno

de hidromiel de la esperanza! (98)

$17 \quad$ A los lugares de adoración en las montañas llegaban "ofrendas humanas" (Ceruti 233) y de objetos, "en el marco del ritual de las capacochas, complejos mecanismos religiosos y políticos que constaban en primera instancia de convergencia en el Cuzco de víctimas sacrificiales y ofrendas procedentes de todo el Tawantinsuyo, y de una segunda instancia de redistribución de las mismas mediante desfiles y procesiones, hasta su destino final en los confines sagrados del imperio (233). Durante el ritual y en varias procesiones se entonan "canciones al Apu y a la Pachamama" (Wissler 104). "A través de la música, ellos recrean una fuerte conexión con el cosmos, ya sea dentro de la comunidad nativa, con el apu o con miles de otros peregrinos" (112). 
La poeta posiciona el origen del colectivo de la enunciación en Mama Ocllo y Manco Cápac ${ }^{18}$, los primeros incas. Con ello construye la legitimidad política de este colectivo sobre un extenso territorio, donde la cordillera es el "hallazgo" o tesoro que permite entendernos de otra forma. La poeta vuelve a posicionar ese origen territorial y político para reclamar una concepción de la historia que vuelve dignos a los latinoamericanos. Con la confianza en el mundo incaico, la madre yacente y de rodillas ("caminas, Madre, sin rodillas"), se transformará en la madre que marcha. Mistral reitera esa construcción retórica donde pliega lo geográfico con lo político.

La política de la estética del poema es el deseo de que los pueblos recuerden el poder que tuvieron en su pasado y se levanten, tornándose un grupo digno de respeto:

¡Por las noches nos acordamos

de bestia negra y plateada,

leona que era nuestra madre

y de pie nos amamantaba! (101)

En el presente, la voz observa una madre arrodillada, por eso llama a recordar un pasado, donde ella era una leona. La voz usa el cliché "era una leona defendiendo a sus hijos", para construir una figura a favor de los pueblos andinos. La forma de describir al indígena, "indio atónico" (100), "peñas arrobadas" (102), y a ella misma como "sonámbula" (101), refieren a un sujeto al que le arrebataron algo y lo dejaron perplejo, como muerto en vida. Esa calidad de fantasmas y humillados es la que la poeta llama a finalizar, mediante una unidad andina que les devuelva lo robado.

El propósito del poema de Mistral es la irrupción de las culturas andinas en el presente. No es la inclusión de ellas en la modernidad, no pide la asimilación o la hibridación. La poeta llama al "enderezarse de las piedras" y a la juntura de ellas, para que dejen de ser piedras rodadas:

18 En Comentarios reales (1609), el Inca Garcilaso de la Vega transcribe la historia del nacimiento de su cultura: "puso nuestro padre el sol estos dos hijos suyos en la laguna Titicaca" (47). "Nuestro inca se llamó Manco Cápac y nuestra coya Mama Ocllo Huaco. Fueron, como te he dicho, hermanos, hijos del sol y de la luna, nuestros padres" (50). 
¡Carne de piedra de la América, halalí de piedras rodadas, sueño de piedra que soñamos, piedras del mundo pastoreadas; enderezarse de las piedras para juntarse con sus almas! ¡En el cerco del valle del Elqui en luna llena de fantasma, no sabemos si somos o somos peñas arrobadas! (101-102)

Tras el enderezarse de las piedras, los que parecen fantasmas volverán a encontrarse con sus cuerpos. La idea de que las rocas pueden ser "carne" humana coincide con la ideación del mundo andino. En una investigación, los antropólogos François Cuynet y Luis Flores comprobaron que "En muchas regiones, los locales rememoran que su antepasado mítico era una piedra con forma humana" ("Cuando el..." 38). De acuerdo con los estudiosos, los andinos reconocían en una piedra de gran tamaño, huaca, al fundador de su territorio. Por ello en los relatos la huaca es el centro espacial que explica la historia del lugar. Mirar la huaca significaba y aún significa estar en una dimensión que abarca toda la historia de la comunidad. La piedra juega el rol de hito geopolítico para marcar un espacio como propio. De manera que Mistral pone en circulación una forma disensual de conocimiento sobre las piedras, donde estas son los antepasados de una comunidad.

La tercera gran forma disensual de Mistral consiste en la valoración de los conocimientos incaicos. La escritora poetiza especialmente la ingeniería empleada en la construcción de caminos y destaca los nombres incaicos de las vías de comunicación que ponen en contacto distintas zonas andinas mediante el tránsito de personas y productos. Lo que era visto comúnmente como un "espacio chileno", ahora es presentado como el "camino del Inca Huayna". Con ello trae a la memoria una nueva forma de estructurar el territorio, donde todos los caminos parten del Cuzco y desde ahí se extienden por el Tawantinsuyo $^{19}$. El historiador del mundo andino, John Murra, pre-

19 Usaremos el nombre Tawantinsuyo empleado en los textos más contemporáneos, como en el de John Murra y en el de Constanza María Ceruti y solo emplearemos Ta- 
cisa el aspecto geocultural tras la palabra: "Tawantinsuyo, es decir el Estado inka [involucra] un vasto territorio y las muchas etnias incorporadas por conquista, diseminadas en múltiples pisos ecológicos, entre serranías, desiertos y quebradas profundas [las que] requirieron de algún sistema que relacionara la periferia con el centro y la costa con el altiplano" (Murra 43).

Mistral comprende que el Tawantinsuyo era una forma de gobierno que implicaba disponer de vías de comunicación entre las diversas partes de ese gran espacio. Recordemos que ya desde el nombre de Tawantinsuyo se aludía al territorio: "Tahuantinsuyo se compone de "tahua" que significa cuatro, y "suyo" que suele interpretarse como región o rumbo, aludiendo a los cuatro puntos cardinales. Los cuatro suyos o regiones que se encontraban hacia el este, oeste, norte y sur, partiendo del Cuzco, eran: Antisuyo (este), Contisuyo (oeste), Chinchasuyo (norte) y Collasuyo (sur)" (Arellano 49). La poeta entiende la importancia de la comunicación en ese espacio y destina una estrofa al camino ubicado en territorio "chileno" o más bien correspondiente a una parte del camino del Collasuyo:

Viboreas de las señales

del camino del Inca Huayna, veteada de ingenierías y tropeles de alpaca y llama de la hebra del indio atónito y del ¡ay! de la quena mágica. (99-100)

El poema permite el ingreso del significante indígena "Inca Huayna”, nombre del undécimo gobernador del imperio incaico ${ }^{20}$. El gobernante recorrió los territorios de Aconcagua y Mapocho, afirmando con su presencia física la pertenencia jurisdiccional, integración que es retomada desde un ángulo más centrado en los aspectos simbólicos

huantinsuyo si la cita original así lo contempla. "El Tahuantinsuyo, a la llegada de los españoles, comprendía el territorio entre Ancasmayo, en la frontera ecuatoriano-colombiana y el río Maule en Chile" (Arellano 49). Dentro del Tahuantinsuyo se encontraba el centro ceremonial Tihuanaku (48).

20 Huaman Poma de Ayala que confecciona la serie histórica de los incas gobernadores refiere: "El onceavo inca Huaina Cápac reinó Cachapoya Quito [...] En ese tiempo saltaron los españoles cristianos a este reino, conquistaron la tierra, mataron a los incas y capitanes y llevaron mucho oro" (50). Los hijos de Huaina Cápac fueron Huascár y Atahualpa (50). 
por Mistral. La poeta pone en ejercicio los nombres de los personajes históricos incas, participándonos de otra historia, diferente de la que impuso la Conquista española.

La detención de Mistral en los caminos incaicos indica su reconocimiento político y epistemológico de los incas. Para esta cultura, los lugares estaban comunicados por "Los caminos [que] recibían el nombre del Inca que los construía. [Este] camino de 4.000 kilómetros que recorría hasta Chile era conocido por el nombre de Huayna Capac Ñan" (Stehberg 44). Mistral destaca de este trayecto cordillerano la ingeniería de su construcción. La poeta exalta lo serpenteado o "viboreado" del trayecto, forma que facilita subir y bajar por los caminos montañosos; a diferencia de las rutas de pendiente recta que plantean dificultades para el viajero. El análisis de "viboreo" aquí planteado agrega un punto a la visión del crítico Cedomil Goic quien indica que "la cuarta estrofa muestra la belleza, ornato de su hechura que imita las formas de la mujer" (Los mitos... 32). Comparto con Goic que una de las imágenes usada por Mistral para la cordillera es el cuerpo tendido de una mujer, pero añado que además hay una representación andina del camino, debido al uso del significante específico "viborear", que remite a la serpiente en la cultura incaica.

La invención de la palabra "viboreas" por parte de Mistral alude a la forma de los caminos y de los canales que transportaban el agua. En este neologismo, Mistral recurre a la imagen de la serpiente porque: "El Amaru o serpiente se vincula con los canales de regadío, con el fluir de las aguas fertilizadoras. Su culto se efectúa en el rito que acompaña la limpieza de los canales" (Hidalgo 57). Los andinos que bajan tocando quenas en el poema, danzan en un rito de adoración a Amaru, la serpiente, y a la vez festejan el agua que navega por los canales.

Mistral le otorga un valor a la caminata por estos senderos, lo cual no era propio de la época en que ella escribe. Esta forma de apartarse de lo hegemónico no es solo de Tala; la crítica Soledad Falabella lo observa también en Poema de Chile: "Mistral llevó a cabo una rearticulación valorativa de elementos relegados y desvalorizados del proyecto modernizador" ("Modernidad literaria..." 139). "Autorizó esta otra forma de educar [a] través de la mamá como educadora ancestral" (140). En Tala, la poeta valora el vínculo de la cultura andina con los caminos y agrega la música con la quena, y los animales del altiplano, la llama y la alpaca, 
con alusión a los beneficios de sus diversos productos. También el texto integra a otros caminantes, más suramericanos, como los mapuches cordilleranos o pehuenches, que sacuden las araucarias para alimentarse con su fruto, el pehuén o piñón. De esta manera, Mistral describe la cordillera como un espacio cultural vivo, donde se cultivan no solo productos alimenticios, sino también la música, los telares y tanto más.

La valoración de los conocimientos, la redescripción de los referentes territoriales y el colectivo de la enunciación que tiene un pasado esplendoroso van produciendo otra percepción acerca del mundo andino. Por ello, es comprensible que el proceso del levantamiento de los pueblos andinos hacia su dignidad ocurre en el presente del nosotros de la enunciación. Respecto del tiempo, basándose en el poema "Nocturno de los tejedores viejos", la crítica Susana Münnich plantea que es irrecuperable, pues interpreta el texto como "una alegoría del dolor de las gentes que viven en la modernidad y no tienen pertenencia ni al trabajo ni a la comunidad en que viven" (245). El poema "Cordillera", por su parte, ofrece la visión contraria: en él Mistral recrea una colectividad que es pasado y presente al mismo tiempo. Esa comunidad oye cómo el Cuzco va volviendo a ser el centro, en palabras de Mistral va retornando a ser "la peana ${ }^{21}$ de la gracia", es decir, el lugar desde el cual están los seres humanos en común-unión:

Vuelven los tiempos en sordo río

y se les oye la arribada, a la meseta de los Cuzcos que es la peana de la gracia. Silbaste el silbo subterráneo a la gente color del ámbar, y desatamos tu mensaje enrollado de salamandra; y el destino que es de nosotros nos exhalas en bocanada. (102)

La comunión de los morenos con el Cuzco funciona como un antídoto para dejar de ser un halalí, o grito de piedras rodadas. Mirar hacia el Cuzco es recuperar la memoria andina localizada. Así, la gente de

${ }_{21}$ La peana es la "base, apoyo o pie para colocar encima una figura u otra cosa" (RAE, 1992). 
color ámbar, dentro de la cual se incluye la hablante, entenderá que "el destino es de nosotros", de los que hemos mantenido el pasado como un río subterráneo.

Para Mistral, la disposición corporal de los andinos es actuar como un "sordo río", esto es, como una corriente que se mantiene porque es capaz de no escuchar la historia blanca colonizadora. Gracias a esa sordera, los tiempos del pasado siguen sucediendo en el presente. El colectivo es sordo para la historia blanca, pero tiene oídos para la historia andina. Ese nosotros tiene la capacidad de oír el llamado de la cordillera y escuchar el "silbo subterráneo". La aliteración del fonema /s/ produce en sí mismo el sonido de silbo del cual se está hablando: se trata de un llamado conspirativo que invita al levantamiento de los pueblos andinos. El nosotros de la enunciación escucha la subversión silenciosa de la arribada de la gente color ámbar.

La retórica de la conspiración está presente en el poema, pues el nosotros que habla informa acerca de la existencia de un mensaje cifrado, en "hemos desatado tu mensaje enrollado en la salamandra". Las cualidades de este animal permiten referir a los conocimientos incaicos: es una especie anfibia, nocturna, si pierde un miembro es capaz de regenerarlo y su hábitat corresponde a las laderas orientales de los Andes del Ecuador y bosques amazónicos hasta el departamento de Cochabamba en Bolivia. Del mismo modo, los conocimientos incaicos han sobrevivido en dos mundos; no han sido oficiales, sino relegados a la parte no visible; pero han sido capaces de mantenerse vivos a pesar de la fractura colonial. Al ser descifrados estos conocimientos, se está exaltando la recuperación del poder interpretativo de los pueblos andinos actuales. La conspiración busca retomar el poder de hacer visible la existencia de las culturas andinas. Manifestación de esa constancia del mundo andino son las caminatas y los cantos a los Apu que han permanecido y que constituyen parte del poema. Estas caminatas no son vestigios, sino la corriente de un río subterráneo:

Otra vez somos los que fuimos, cinta de hombres, anillo que anda

viejo tropel, larga costumbre en derechura a la peana, donde quedó la madre augur 
que desde cuatro siglos llama, en toda noche de los Andes y con grito que es lanzada (102-103)

La voz enunciadora menciona la larga costumbre de caminar por la cordillera en forma de zigzag. Antes de cuatro siglos, es decir antes del siglo XVI, puesto que el poema se escribió en el siglo XX, la costumbre era peregrinar hacia la madre augur, el Cuzco. "Otra vez" dice el texto, indicando que ese pasado no ha estado nunca cancelado, en otras palabras, nunca ha sido un pretérito, siempre ha sido un presente.

A pesar de los intentos de fragmentación colonizadora que rompieron el anillo de la alianza, los andinos vuelven una y "otra vez" a experimentarse como colectividad, por ejemplo, cuando cantan:

Otra vez suben nuestros coros

y el roto anillo de la danza,

por caminos que eran de chasquis,

y en pespunte de llamaradas.

Son otra vez adoratorios

jaloneando la montaña,

y la espiral en que columpian

mirra-copal, mirra-copaiba

ipara tu gozo y nuestro gozo

balsámica y embalsamada! (103)

En el rito de subir la montaña cantando, la cordillera vuelve a ser espacio adoratorio. La plenitud corporal se alcanza por el proceso de subir la montaña entonando la canción. La totalidad de la experiencia se completa con el olor, ya que los participantes respiran incienso de copal, y con ello huelen los mismos olores antiguos de las mirras latinoamericanas ${ }^{22}$. El sensorium del olfato vuelve "otra vez", trayendo al presente los reconocibles olores del pasado.

\section{Conclusiones: el mundo transandino de Mistral}

El verso "somos los que fuimos", expresado en el poema "Cordillera" sintetiza su comprensión acerca del mundo indígena transandino, conci-

\footnotetext{
22 "Copaiba, Canime, Maracaibo Balsam", "native to Brazil and Venezuela", "the Copal is used in lacquers, massage preparations, medicines and paint" (Duke 192-196).
} 
biéndolo como un pasado que es presente, en tanto su cultura está viva hasta el día de hoy. Mistral expresa, a través de la valoración de lo indígena y de lo andino, su polémica contra los efectos de la colonización. La cordillera concebida por la poeta es el espacio donde conviven pasado y futuro, sin jerarquías y sin linealidades temporales arbitrarias.

Mistral no se erige como apoderado plenipotenciario de subjetividades andinas. La escritora crea una discursividad donde ella se incluye en el nosotros de las subjetividades apocadas por la hegemonía. Ella es "trans" porque escribe cuando está lejos de Chile y de América Latina; y es "trans" cuando afirma el pasado en el presente de su enunciación. Ese "trans" es también su distancia estética con los repertorios artísticos de la época. En Tala, sus formas disensuales fueron la creación de otros referentes territoriales, la invención de un nosotros andino y la valorización de los conocimientos incaicos. En la escritura de la poeta, las prácticas y pensamientos del antiguo Tawantinsuyo incaico conviven con las ideas del siglo XX y anuncian las revueltas del XXI contra la nación, las que están deconstruyendo la idea de nación y llevan a repensar antiguas y más extensas zonas culturales, tal como lo imaginó la poeta Premio Nobel.

\section{Referencias bibliográficas}

Arellano, Fernando. El arte hispanoamericano. Caracas, Universidad Católica Andrés Bello, 1988.

Ayala, Felipe Huaman Poma De. Nueva crónica y buen gobierno. Tomo II. Ed. y notas de Carlos Araníbar. Lima, Biblioteca del PerúColección Bicentenario, 2017.

Bernaschina, Vicente y Marco Thomas Bosshard. "Introducción: orientaciones transandinas para los estudios andinos". Revista Iberoamericana, vol. 253, no. 81, 2015, pp. 925-935.

Ceruti, María Constanza. "Santuarios de altura en la región de Laguna Brava". Chungará. Revista de Antropología Chilena, vol. 2, no. 35, 2003, pp. 233-252.

Commelin, Pierre. Mitología griega y romana. Buenos Aires, Editorial el Ateneo, 2018.

Concha, Jaime. Gabriela Mistral. Barcelona, Júcar, 1987.

Cornejo Polar, Antonio. "El indigenismo y las literaturas heterogéneas: su doble estatuto socio-cultural". Revista de Crítica Literaria Latinoamericana, vol. 7-8, no. 4, 1978, pp. 7-21. 
Cuynet, Francois y Luis Flores. "Cuando el mito se vuelve piedra: memorias alrededor de estelas Pukara en el norte del Titikaka, Perú". Chungará. Revista de Antropología Chilena, vol. 1, no. 49, 2017, pp. 35-48.

Duke, James y Judith L. duCellier. "CRC handbook of alternative cash crops”. Economic Botany, vol. 50, no. 25, 1996, pp. 192-196.

Estébañez, Demetrio. Diccionario de términos literarios. Madrid, Alianza, 1999.

Falabella, Soledad. "Modernidad literaria y la entrada de las mujeres a la esfera pública en los discursos de Bello, de Hostos y Mistral". Revista Chilena de Literatura, no. 82, 2012, pp. 119-141.

Gazmuri, Cristián. Historia de Chile (1891-1994): política, economía, sociedad, cultura, vida privada, episodios. Santiago de Chile, Pontificia Universidad Católica de Chile, 2012.

George Gordon Byron. Mazeppa. Sevilla, Imprenta Atienza, 1851.

Goic, Cedomil. "Himnos americanos y extravío: 'Cordillera' de Gabriela Mistral". Historia y crítica de la literatura latinoamericana. Vol. 2. Del Romanticismo al Modernismo. Coord. Cedomil Goic. Barcelona, Editorial Crítica, 1988.

Los mitos degradados. Ensayos de comprensión de la literatura hispanoamericana. Ámsterdam, Rodopi, 1992.

Greene, Roland (Ed.). The Princeton encyclopedia of poetry. Oxford, University Press, 2012.

Grimal, Pierre. Diccionario de mitología griega y romana. Buenos Aires, Paidós, 1981.

Hidalgo, Jorge. Historia andina en Chile. Santiago de Chile, Editorial Universitaria, 2014.

Mignolo, Walter. "La opción de-colonial: desprendimiento y apertura. Un manifiesto y un caso". Tabula rasa, no. 8. Bogotá, 2008, pp. 243-281.

Mistral, Gabriela. Tala. Buenos Aires, Sur, 1938.

Münnich, Susana. Gabriela Mistral. Soberbiamente transgresora. Santiago de Chile, LOM Ediciones, 2005.

Murra, John. El mundo andino: población, medio ambiente y economía. Lima, Pontificia Universidad Católica del Perú, 2002.

Ostria, Mauricio. "Americanismo e indigenismo en Gabriela Mistral". Boletín de Educación, no, 36, 2005, pp. 95-104. 
Oxford University Press (Ed.). "Mar de los sargazos". Atlas of the world. Oxford, Oxford University Press, 2014.

Real Academia Española. "Cíngulo". Diccionario de la lengua española. Madrid, Espasa Calpe, 1992.

Rancière, Jacques. El espectador emancipado. Trad. Ariel Dilon. Buenos Aires, Manantial, 2013.

Rojo, Grínor. Dirán que está en la gloria... (Mistral). Santiago de Chile, Fondo de Cultura Económica, 1997.

Sepúlveda Eriz, Magda. Gabriela Mistral. Somos los andinos que fuimos. Santiago de Chile, Cuarto Propio, 2013.

Subercaseaux, Bernardo. Historia de las ideas y de la cultura en Chile: desde la Independencia hasta el Bicentenario. Volumen II. Santiago de Chile, Editorial Universitaria de Chile, 2011.

Stehberg, Rubén. Instalaciones incaicas en el norte y centro semiárido de Chile. Santiago de Chile, Biblioteca Nacional de ChileCentro de investigaciones Barros Arana, 1995.

Vega, Inca Garcilaso De la. Obras completas. Tomo II. Comentarios reales. Lima, Biblioteca Nacional del Perú, 2015.

Vergara y Velasco, Francisco. Geografía general de Colombia. Bogotá, Camacho Roldán y Tamaño, 1910.

Wissler, Holly. “Q'eros, Perú: la regeneración de relaciones cosmológicas e identidades específicas a través de la música". Antropológica, no. 28. Lima, 2001, pp. 93-116. 